\title{
Producción de biogás a partir de estiércol de gallina, utilizando colectores solares
}

\section{Production of biogas from chicken manure using solar collectors}

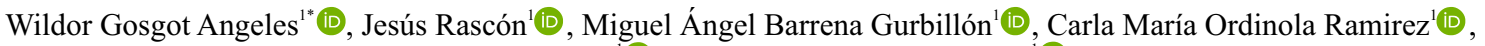
Manuel Oliva ${ }^{\mathbb{D}}$, Yesica Montenegro Santillan ${ }^{1}$ (D)

\section{RESUMEN}

La producción de biogás a partir de residuos biodegradables se presenta como una alternativa energética sostenible en comparación a los combustibles fósiles, causantes de las emisiones de gases de efecto invernadero. EL objetivo de la investigación fue evaluar la producción de biogás a partir de estiércol de gallina de la granja avícola de la UNRTM -A, durante 15 días a temperatura ambiente, midiendo parámetros de operación (temperatura, producción de biogás y calidad de biogás en $\mathrm{CH}_{4}, \mathrm{H}_{2} \mathrm{~S}, \mathrm{CO}, \mathrm{O}_{2}, \mathrm{CO}_{2}$ ), precisando una alternativa de aprovechamiento adecuado de este residuo, para reducir problemas de contaminación ambiental adversos a su disposición final, produciendo una alternativa limpia, es así que la evaluación consistió en un sistema de digestión anaerobia a nivel de laboratorio, constituido de biodigestores de botellas PET de $1700 \mathrm{~mL}$ y gasómetros de botellas PET de $1700 \mathrm{~mL}$ calibrados cada $20 \mathrm{~mL}$, ambas botellas conectadas a una manguera para medir el biogás por desplazamiento de agua. En el sistema se aplicó 02 tratamientos, alimentando los biodigestores con: T1 (estiércol de gallina y agua en proporción 1:2) y T2 (estiércol de gallina y biol en proporción 1:2, para acelerar el proceso de digestión anaeróbica debido a la presencia de bacterias Metanogénicas), 04 repeticiones por tratamiento y 02 colectores solares con aislante térmico. Los resultados demostraron que el T2, fue el más eficiente con una producción de biogás promedio de 751,45 $\mathrm{mL} /$ día, y un rango mayor de $1200 \mathrm{~mL}$, a comparación del T1 el cual presentó una producción promedio de 209,6 mL / día, y un rango mayor de $400 \mathrm{~mL}$, a temperatura promedio interna de $24{ }^{\circ} \mathrm{C}$ y temperatura externa de $22{ }^{\circ} \mathrm{C}$ para ambos tratamientos. En cuanto a calidad del biogás, para el componente $\mathrm{CH}_{4}$, en ambos tratamientos fue muy bajo, empezando su producción para T2 a partir del día 7 y para el T1 a partir del día 11.

Palabras clave: energías renovables, metano, energía solar.

\begin{abstract}
The production of biogas from biodegradable waste is presented as a sustainable energy alternative to fossil fuels, which cause greenhouse gas emissions. The objective of the research was to evaluate the production of biogas from chicken manure from the poultry farm of UNRTM - A, for 15 days at room temperature, measuring operating parameters (temperature, biogas production and biogas quality in $\mathrm{CH}_{4}, \mathrm{H}_{2} \mathrm{~S}, \mathrm{CO}, \mathrm{O}_{2}, \mathrm{CO}_{2}$ ), specifying an alternative of adequate use of this waste, Thus, the evaluation consisted of an anaerobic digestion system at laboratory level, consisting of $1700 \mathrm{~mL}$ PET bottle biodigesters and $1700 \mathrm{~mL}$ PET bottle gasometers calibrated every $20 \mathrm{~mL}$, both bottles connected to a hose to measure the biogas by water displacement. In the system 02 treatments were applied, feeding the biodigesters with: T1 (chicken manure and water in 1:2 ratio) and T2 (chicken manure and biol in 1:2 ratio, to accelerate the anaerobic digestion process due to the presence of Methanogenic bacteria), 04 replicates per treatment and 02 solar collectors with thermal insulation. The results showed that T2 was the most efficient with an average biogas production of $751.45 \mathrm{~mL} /$ day, and a range greater than $1200 \mathrm{~mL}$, compared to T1 which presented an average production of $209.6 \mathrm{~mL} / \mathrm{day}$, and a range greater than $400 \mathrm{~mL}$, at an average internal temperature of $24^{\circ} \mathrm{C}$ and external temperature of $22^{\circ} \mathrm{C}$ for both treatments. In terms of biogas quality, for the $\mathrm{CH}_{4}$ component, in both treatments it was very low, starting its production for T2 from day 7 and for T1 from day 11.
\end{abstract}

Keywords: renewable energies, methane, solar energy.

\footnotetext{
${ }^{1}$ Universidad Nacional Toribio Rodríguez de Mendoza de Amazonas, Instituto de Investigación para el Desarrollo Sustentable de Ceja de Selva, Chachapoyas, Perú

"Autor de correspondencia. E-mail: wildor.gosgot@untrm.edu.pe
} 


\section{INTRODUCCIÓN}

La mayor preocupación en el mundo es la influencia que tiene el calentamiento global y el cambio climático en los diversos sectores de la población, a causa del uso de los recursos naturales y la disposición inadecuado de residuos biodegradables generados, a partir de una actividad insostenible (Constantini et al., 2018). La ganadería contribuye como una generadora en gran manera de las emisiones de gases de efecto invernadero, causantes de riesgos significativos para la salud pública y el medio ambiente (Pramanik et al., 2019; Tayyab et al., 2019). Por otra parte, los problemas energéticos y la disponibilidad limitada de combustibles fósiles especialmente en zonas rurales, se han convertido en un tema prioritario por atender, mediante alternativas de valorización energéticas (Llamas, 2019), donde se aprovechen de manera sostenible los residuos biodegradables, para la producción de biogás (Pramanik et al., 2019; Sev et al., 2019). Es así que la actual reforma energética conduce a sustituir la energía eléctrica por biogás, por ser una fuente de energía limpia y renovable (Martínez, 2015; Hagos et al., 2017).

Una de las tecnologías de valorización de residuos, es la utilización de biodigestores (Burg et al., 2018), donde se obtiene biogás de la fermentación anaerobia de la biomasa por microorganismos (Bong et al., 2018), descomponiendo macromoléculas para la producción de biogás (Corrales et al., 2015). Sin embargo, estos microorganismos descomponedores de la biomasa requieren ciertas condiciones adecuadas para su buen desarrollo (Reyes, 2016). Algunas de estas condiciones, están enfocados en el sustrato manejado para biodigestar y las condiciones a la que está expuesta (Abbasi et al., 2012), principalmente la temperatura, el pH, relación $\mathrm{C} / \mathrm{N}$ y el tiempo de retención hidráulica (TRH) del sustrato dentro del biodigestor que juega un papel muy importante (Mussoline et al., 2013; Kainthola et al., 2019). Si dichos microorganismos, no se encuentran en óptimas condiciones, los resultados de la digestión anaeróbica serán expresado en bajos rendimientos y baja calidad del biogás (Kaint- hola et al., 2019). Al mismo tiempo, para tal efecto la velocidad de degradación depende en gran parte de la temperatura, es así que cuando aumenta la temperatura, menor será el tiempo de retención (Varnero, 2011; Reyes, 2019), debido a la activación alta de masas microbianas dentro del sistema (Al-Rubaye et al., 2018).

Según Ortiz et al. (2015) y Pedraza et al. (2016), los microorganismos metanogénicos como son: Methanobacterium spp y Methanococcus spp, productores de metano $\left(\mathrm{CH}_{4}\right)$, mayor componente del biogás, entran en activación a temperaturas variables de 27 y $34{ }^{\circ} \mathrm{C}$ con producción mayor de biogás de $0,375 \mathrm{~cm}^{3}$ $\mathrm{CH}_{4} /$ día, durante 15 días y (Tankin et al., 2015), determinaron que el rendimiento de un digestor anaerobio, es bajo cuando la temperatura se reduce, y el $\mathrm{pH}$ se establece en rangos inferiores de 6,5, con obtención de biogás por debajo de $100 \mathrm{~mL} /$ día, pero cuando las temperaturas suben, el biogás aumenta a niveles de 100 - $270 \mathrm{~mL} /$ día. En cuanto C/N de 0,5, con una concentración de carbono alrededor de $156 \mathrm{mg} / \mathrm{L}$, ayuda a mantener la abundancia de microorganismos presentes en el biodigestor (Chini et al., 2019).

Para superar estos desafíos existen diversas técnicas, una de ellas es la digestión de sustratos de fácil degradación, haciendo eficiente el rendimiento del proceso anaeróbico (Kainthola et al., 2019). Así lo demuestran Cuba y Lescano (2007), quienes produjeron biogás a partir de estiércol de gallina mediante un biorreactor de acero inoxidable con capacidad 264,21 L, empleando como sustrato de alimentación $29,83 \mathrm{Kg}$ de estiércol de gallina mezclado con $12,78 \mathrm{~L}$ de lodo activado y 88,34 L de agua, obteniendo una producción diaria máxima de $0,1928 \mathrm{Kg}$ de biogás durante 26 días y una producción total de $6,92 \mathrm{Kg}$ al final del proceso, concluyendo que el estiércol de gallina es un sustrato potencial para producir biogás.

Es por ello, que el objetivo de esta investigación es evaluar la producción de biogás partir de estiércol de gallina y biol, a nivel experimental, midiendo parámetros de operación como la temperatura, $\mathrm{pH}$, radiación solar, TRH, producción de biogás y calidad de biogás 
en $\mathrm{CH}_{4}, \mathrm{H}_{2} \mathrm{~S}, \mathrm{CO}, \mathrm{O}_{2}, \mathrm{CO}_{2}$ y su interrelación entre ambas en relación al rendimiento de biogás.

\section{MATERIALES Y MÉTODO}

\section{Ubicación}

La investigación fue desarrollada en el Laboratorio de Energías Renovables de la Universidad Nacional Toribio Rodríguez de Mendoza de Amazonas en la ciudad de Chachapoyas.

\section{Diseño experimental}

Para la fase experimental se aplicó el Diseño Completamente al Azar (DCA), evaluando 02 tratamientos y 04 repeticiones por tratamiento, disponiendo biodigestores en colectores solares, durante 15 días, teniendo como variable respuesta el volumen de biogás producido dentro de los sistemas. Los tratamientos consintieron según mezcla de sustrato utilizado es así que para: (T1) se empleó estiércol de gallina + agua en proporción 1:2 v/v, mientras que para el (T2) se empleó estiércol de gallina + biol en proporción 1:2 $\mathrm{v} / \mathrm{v}$.

Diseño y construcción del sistema de producción de biogás

\section{Colector solar}

El sistema de producción de biogás, consistió en dos colectores solares a base de madera ishpingo (Figura 1S y 2S). Para la captación de la radiación solar se dio $30^{\circ}$ de inclinación a cada colector. Al interior de los colectores se colocó como aislante térmico tecnopor y papel aluminio. Consecuente se dispusieron las botellas PVC de $1700 \mathrm{~mL}$ los cuales eran los biodigestores y la sonda del termo hidrómetro para medir la temperatura a diario (Figura 3S). Para finalizar el sistema se cubrió con una mica transparente donde irradiará el sol.

\section{Sistema para captura de biogás}

Para la captura y medición de biogás producido dentro del sistema, se trabajó por desplazamiento de líquidos, el cual consistió en una botella PVC de 1700 mL como gasómetro, graduado con una jeringa de $20 \mathrm{~mL}$, con una manguera de benoclides en su interior y una manguera de salida en la parte superior de la botella el cual tenía una llave para medir la composición de biogás producido. Las botellas estuvieron con contenido de agua, dispuestas de forma invertida en una bandeja con agua (Figura 4S).

\section{Evaluación de los biodigestores}

\section{Preparación de la mezcla}

La mezcla para alimentar los biodigestores, si hicieron dos mezclas, una con agua y otra con biol (Tabla S1 y Figura 5S).

\section{Medida de pHy la temperatura del sustrato}

En la investigación la medida de los parámetros de temperatura y alcalinidad $(\mathrm{pH})$ del sustrato se midieron con un Multiparamétrico en el laboratorio de suelos y aguas de la Universidad Nacional Toribio Rodríguez de Mendoza. Para ello se separó una muestra de $80 \mathrm{~mL}$ por tratamiento. Luego se procedió a llenar los biodigestores al $80 \%$ equivalente a $1360 \mathrm{~mL}$ con la mezcla preparada para ambos tratamientos ( $\mathrm{T} 1$ y $\mathrm{T} 2$ ).

Medida de parámetros de operación dentro del sistema

La evaluación de los parámetros dentro del sistema fue en un periodo de 15 días, tiempo óptimo para evaluar la producción de metano $\left(\mathrm{CH}_{4}\right)$, mayor componente en el biogás, por el cual presenta valores energéticos produciendo combustión al encontrarse más del 50\%. Los parámetros medidos fueron los indicados en la Tabla S2. Con respecto a la temperatura se midió a través de un termo hidrómetro todos los días en los horarios 8 am, 12 pm y 4 pm (Figura 6S). En cuanto a la producción y calidad del biogás se midió todos los días a las $4 \mathrm{pm}$.

\section{Lectura del rendimiento de producción de biogás}

Para el rendimiento de biogás, se midió por desplazamiento de líquido, conduciéndolo el biogás hacia una botella de plástico graduado con contenido de agua, que por presión será desplazado.

\section{Lectura de la calidad del biogás}

La calidad de biogás se midió con el equipo de medición de gases con los principales gases $\mathrm{CH}_{4}, \mathrm{H}_{2} \mathrm{~S}, \mathrm{CO}$, $\mathrm{O}_{2}, \mathrm{CO}_{2}$ (Figura 7S).

\section{Análisis estadístico}

Para el análisis estadístico de los datos obtenidos por 
tratamiento, fueron procesados en Excel, realizando un análisis de varianza (ANOVA) con nivel de confianza al 95\% $(\mathrm{p}<0,05)$, determinando las diferencias entre los tratamientos $(\mathrm{T} 1-\mathrm{T} 2)$, en relación a los parámetros de operación del sistema y el rendimiento de biogás producido en un periodo de 15 días.

\section{RESULTADOS}

\section{Medida de pH y temperatura del sustrato}

En un sistema de digestión anaerobia, a medida que las bacterias influyentes, se van activando para la formación del biogás, estas requieren ciertas condiciones adecuadas para su buen desarrollo, los cuales están enfocados en el sustrato para biodigestar y las condiciones a la que están expuestas y dentro de esta se encuentra la temperatura y el $\mathrm{pH}$, que al no encontrarse en óptimas condiciones, los resultados de la digestión anaeróbica será expresado en bajos rendimientos, haciendo prolongado el TRH y baja calidad del biogás producido, con respecto al análisis de la temperatura y $\mathrm{pH}$ del sustrato utilizado en la investigación, estas se encontraron en rangos óptimos, iniciando con un $\mathrm{pH}$ neutro, para dar inicio al proceso de digestión del sustrato a biodigestar.

\section{Medida de parámetro de operación}

\section{Temperatura}

Dentro del registro de temperaturas durante los 15 días de evaluación, se obtuvo un rango de temperatura interna promedio de $24^{\circ} \mathrm{C}$ y temperatura externa promedio de $22^{\circ} \mathrm{C}$ (Figura $8 \mathrm{~S}$ ).

Tras aplicar el ANOVA, para la temperatura al interior de los colectores solares, se ve que no hay diferencias significativas entre los tratamientos $(\mathrm{F}=0,0711$, Valor critico $F=4,1959)$.

\section{Producción de biogás}

El tratamiento T2, durante el periodo de evaluación, se obtuvo la mayor producción de biogás con un rango mayor de $1200 \mathrm{~mL}$ el cual dentro de la investigación se considera como el sistema más eficiente, a comparación del tratamiento $\mathrm{T} 1$ en el cual se obtuvo valores máximos de $400 \mathrm{~mL}$ de biogás (Figura 9S).

Tras aplicar el ANOVA, para la producción de biogás, se ve que hay diferencias significativas entre los tratamientos $(\mathrm{F}=34,3625$, Valor critico $\mathrm{F}=4,1959)$.

Composición del biogás producido (calidad)

La composición del biogás para el T2, presentó mayor proporción con referencia a los componentes del biogás como es $\mathrm{CH}_{4}(\mathrm{ppm}), \mathrm{CO}_{2}(\% \mathrm{~V}), \mathrm{H}_{2} \mathrm{O}(\mathrm{ppm}), \mathrm{CO}$ $(\mathrm{ppm})$ y con referencia al oxigeno $\left(0_{2}\right)$, es un dato establecido por el equipo, de valor 20.9 en \%V. Además, en cuanto al componente $\mathrm{CH}_{4}$, en ambos tratamientos fue muy bajo, empezando su producción para T2 a partir del día 7 y para el T1 a partir del día 11 (Figura 10S).

\section{DISCUSIONES}

Según Redondo (2015), los microorganismos que se desarrollan dentro de un sistema de digestión anaerobia, necesitan sustratos con $\mathrm{pH}$ neutros, es así que recomienda para: los fermentativos se necesita un $\mathrm{pH}$ entre los rangos de 7.2 - 7.4, para los Acetogénicos entre 7.0 - 7.2 y para los Metanogénicos un rango de pH que va entre los 6.5 - 7.5, en este contexto en la investigación se obtuvo un $\mathrm{pH}$ del sustrato a biodigestar entre los valores de 6.7 y 6.9 , lo que se puede considerar que el pH del sustrato se encontró en las condiciones adecuadas para dar inicio al desarrollo de los microorganismos puesto que es neutro.

Los microorganismos fermentadores de un biodigestor, requieren temperaturas no menores a $\operatorname{los} 35^{\circ} \mathrm{C}$, al depender de esta su actividad y producción de gas (Corrales et al., 2015). Es así que la velocidad de degradación depende en gran parte de la temperatura, puesto que cuando aumenta la temperatura menor será el tiempo de retención (Reyes, 2019), debido a la activación alta de masas microbianas dentro del sistema (Al-Rubaye et al., 2018). Aunado a esto en la investigación se obtuvo registros de temperaturas desde 17 ${ }^{\circ} \mathrm{C}$ hasta $41{ }^{\circ} \mathrm{C}$, ideales para producir biogás, lo que a su vez corrobora según Ortiz et al., (2015) y Pedraza et al., (2016), quienes dan a conocer que los microorganismos metanogénicas como son: Methanobacterium spp y Methanococcus spp, productores de metano $\left(\mathrm{CH}_{4}\right)$, mayor componente del biogás, entran en activación a temperaturas variables de 27 y $34^{\circ} \mathrm{C}$. 
Tankin et al., (2015), determinaron que el rendimiento de un digestor anaerobio, es bajo cuando la temperatura se reduce, y el pH se establece en rangos inferiores de 6.5, con obtención de biogás por debajo de 100 $\mathrm{mL} /$ día, pero cuando las temperaturas suben, el biogás aumenta a niveles de 100 - $270 \mathrm{~mL} /$ día, es así que Cuba y Lescano (2007), produjeron biogás a partir de 29,83 $\mathrm{Kg}$ de estiércol de gallina con 12,78 L de lodo activado y 88,34 L de agua, de los cuales obtuvieron una producción diaria máxima de $0,1928 \mathrm{Kg}$ de biogás durante 26 días y una producción total de $6,92 \mathrm{Kg}$. En la investigación en la cual se trabajó con estiércol de gallina en mezclas de agua y biol, constituido en dos tratamientos (T1 y T2), el tratamiento 2, fue el más eficiente con una producción de biogás promedio de $751.45 \mathrm{~mL} /$ día, y un rango mayor de $1200 \mathrm{~mL}$, a comparación del T1 el cual presentó una producción promedio de 209. $6 \mathrm{~mL}$ / día, y un rango mayor de $400 \mathrm{~mL}$, a temperatura promedio interna de $24^{\circ} \mathrm{C}$ y temperatura externa de $22{ }^{\circ} \mathrm{C}$ para ambos tratamientos y con respecto a la calidad del biogás producido, para el componente $\mathrm{CH}_{4}$, en ambos tratamientos fue muy bajo, empezando su producción para T2 a partir del día 7 y para el T1 a partir del día 11, a esto al final del proceso, concluimos que el estiércol de gallina es un sustrato potencial para producir biogás.

\section{CONTRIBUCIÓN DE LOS AUTORES}

Todos los autores participaron en la conceptualización, metodología, investigación, redacción del manuscrito inicial, revisión bibliográfica, y en la revisión y aprobación del manuscrito final.

\section{CONFLICTO DE INTERESES}

Los autores declaran no tener conflicto de intereses.

\section{REFERENCIAS BIBLIOGRÁFICAS}

Abbasi, T., S. M. Tauseef, y S. A. Abbasi. 2012. "Anaerobic digestion for global warming control and energy generation-An overview". Renewable and Sustainable Energy Review
$16(5): 3228-3242$.

Al-Rubaye, H., J. Smith, M. Shivashankaraiah, J. Yu, S. Karambelkar, y M. Ghorbanian. 2018. "El impacto del tiempo de retención hidráulica y la temperatura de operación en la producción de biocombustibles y el proceso de tratamiento de aguas residuales". Ingeniería Química e Intensificación del Proceso de Procesamiento 129: 171-180.

Bong, C.P.C., L. Y. Lim, C. T. Lee, J. J. Klemeš, C. S. Ho, y W. S. Ho. 2018. "The characterisation and treatment of food waste for improvement of biogas production during anaerobic digestion - A review". Journal of Cleaner Production 172: 1545-1558.

Burg, V., G. Bowman, M. Haubensak, U. Baier, y O. Thees. 2018. "Valorization of an untapped resource: energy and greenhouse gas emissions benefits of converting manure to biogas through anaerobic digestion". Resources, Conservation and Recycling 136: 53-62.

Chini, A., A. C. Bolsan, C. E. Hollas, F. G. Antes, G. Fongaro, H. Treichel, y A. Kunz. 2019. "Evaluation of deammonification reactor performance and microrganisms community during treatment of digestate from swine sludge CSTR biodigester". Journal of environmental management 246: 19-26.

Corrales, L. C., D. M. Romero, J. A. Macías, y A. M. Vargas. 2015. "Bacterias anaerobias: procesos que realizan y contribuyen a la sostenibilidad de la vida en el planeta". Nova 13 (24): 55 82.

Cuba, W. A. y N. A. Lescano. 2007. Obtención de biogás a partir de estiércol de gallinas procedente de la grannja avícola LescanoChicama utilizando un biorreactor anaerobio de lecho fijo. Universidad Nacional de Truji1lo. Trujillo (Perú).

Hagos, K., J. Zong, D. Li, C. Liu, y X. Lu. 2017. “Anaerobic co-digestion process for biogas production: Progress, challenges and perspec- 
tives". Renewable and Sustainable Energy Reviews 76: 1485-1496.

Kainthola, J., S. Kalamdhad, y V. Goud. 2019. A review on enhanced biogas production from anaerobic digestion of lignocellulosic biomass by different enhancement techniques. Process Biochemistry 84: 81-90.

Llamas, M. 2015. Estudio del efecto del rango de temperatura sobre la producción de biohidrógeno por digestión anaerobia a partir de residuos orgánicos. Tesis de Grado. Universidad de Cádiz. Cádiz(España).

Martínez, M. 2015. "Producción potencial de biogás empleando excretas de ganado porcino en el estado de Guanajuato". Nova scientia 7 (15): 96-115.

Mussoline, W., G. Esposito, A. Giordano, y P. Lens. 2013. "The Anaerobic Digestion of Rice Straw: A Review". Critical Reviews in Environmental Science and Technology 43 (9): 895-915.

Ortiz, J. L., J. A. Rodríguez, Á. M. Cajiao, y J. I. Maldonado. 2015. "Caracterización fenotípica de metanogénicas aisladas de un sistema di-fafs operado con lixiviado, agua residual y estiércol porcino". Limentech, Ciencia y Tecnología Alimentaria 13 (2): 108-122.

Pedraza, A. C., J. A. Chona, J. I. Maldonado, y J. L. Carrillo. 2016. Estudio cinético de bacterias metanogénicas a diferentes temperaturas. Bistua revista de la facultad de ciencias básicas 14 (1): 38-46.

Pramanik, S. K., F. Suja, S. Zain, y B. Pramanik. 2019. "The anaerobic digestion process of biogas production from food waste: Prospects and constraints". Bioresource Technology Reports 8: 100310 .

Reyes, E. A. (2016). "Producción de biogás a partir de biomasa". Revista Cientifica de FAREMEsteli 17: 11-22.

Tankin, A., J. Martin, J. Castano, R. Ciotola, J. Rosenblum, y M. Bisesi. 2015. "Impact of organic loading rates on the performance of variable temperature biodigesters". Ecological Engineering 78: 87-94.

Tayyab, A., Z. Ahmad, T. Mahmood, A. Khalid, S. Qadeer, S. Mahmood, y M. Anjum. 2019. "Anaerobic co-digestion of catering food waste utilizing Parthenium hysterophorus as co-substrate for biogas production". Biomass and Bioenergy 124: 74-82.

Varnero, M. T. 2011. Manual de biogás. Santiago de Chile (Chile): FAO. 